\title{
À procura da literatura austríaca: da construção à análise de um mito
}

\section{Ruth Bohunovsky ${ }^{1}$}

\begin{abstract}
Sie fragen mich, ob man von einer spezifisch österreichischen Literatur sprechen kann. Die Bejahung dieser Frage ist mir selbstverständlich. Die spezifische Besonderheit der österreichischen Literatur ist zwar nicht leicht zu bestimmen, aber jeder empfindet sie.
\end{abstract}

Thomas Mann

Die Frage, ob es eine österreichische Literatur gebe, ist schon in die Jahre gekommen und daher verdientermaßen auch schäbig geworden. [...] Wissenschaftstheoretisch kann man diese Fragestellung sehr wohl aber auch als obsolet abtun. [...] Zum andren wiederum verstört doch - und das wäre auch als ein deutscher Nationalismus ,à rebours“ zu denken -, wenn da plötzlich Thomas Bernhard oder Peter Handke oder Ingeborg Bachmann schlicht als deutsche Dichter figurieren und fraglos in den Zusammenhang der „deutschen Literatur“ eingebunden werden.

Wendelin Schmidt-Dengler

\begin{abstract}
This paper presents an overview of the central arguments of some studies and essays about Austrian literature (Menasse; Schmidt-Dengler; Sebald, Weiss, Zeyringer) that are concerned with the existence of a difference between the Austrian and other German language literatures. To illuminate the core points of these discussions, we will compare them to representative arguments about Austrian literature from post-war decades. The aim is to show that contemporary German literature studies in Austria do not dedicate themselves any more to the construction of an "Austrian myth" or to the search of an alleged "essence" of national literature. On the contrary, the construction of an "Austrian myth" has been replaced by analyses of this myth as well as the social and historical contexts that surround the literary
\end{abstract}

1 Doutora em Linguística Aplicada pela Universidade Estadual de Campinas (Unicamp). Professora Adjunta na Universidade Federal do Paraná (UFPR). Email: ruth.bohunovsky@uol.com.br. 


\section{Bohunovsky, R. - À procura da literatura austríaca}

production of the country. In spite of the argumentative discrepancies between the different approaches - which are closely aligned with the formation of the Austrian nation -, the continuing insistence on the part of contemporary German literature studies in Austria on the distinctiveness of Austrian literature is interesting to observe.

Key-words: Austrian literature - Austrian identity - history of literature

Zusammenfassung: In diesem Beitrag werden zentrale Argumente wissenschaftlicher Publikationen und Aufsätze (MENASSE; SCHMIDT-DENGLER; SEBALD, WeISS, ZEYRINGER) über die österreichische Literatur zusammengefasst und näher beleuchtet, insbesondere jene, die sich auf die Eigenständigkeit der österreichischen Literatur neben anderen Literaturen in deutscher Sprache beziehen. Um diese Debatten in ihren historischen Zusammenhang zu stellen, werden sie mit theoretischen Ansätzen v.a. der Nachkriegszeit verglichen, die sich dem selben Thema widmen. So können wir feststellen, dass sich die jüngere österreichische Germanistik nicht mehr der Konstruktion eines „österreichischen Mythos“ widmet, genauso wenig wie der Diskussion über das, was das „Wesen“ der österreichischen Literatur ausmachen könnte. Diese Konstruktion wurde von der Analyse des „österreichischen Mythos“ abgelöst, sowie von Diskussionen über die sozio-historischen Kontexte, in denen österreichische Literatur produziert und rezipiert wird. Trotz dieser argumentativen Unterschiede zwischen den verschiedenen Ansätzen - die ihrerseits wieder eng mit der historischen Entwicklung des Staates Österreich verbunden sind -, ist es interessant festzustellen, dass es weiterhin ein signifikatives Bestehen auf die Besonderheit der österreichischen Literatur gibt, die oft übersehen wird - im Sinne der oben angeführten Germanisten und Schriftsteller jedoch nicht übersehen werden sollte.

Schlüsselwörter: österreichische Literatur - österreichische Identität - Literaturgeschichte

Resumo: Este artigo procura resumir e ilustrar argumentações centrais de estudos teóricos e ensaios sobre a literatura austríaca (MENASSE; SCHMIDT-DENGLER; SEBALD, WeISS, ZEYRINGER) que se referem, especificamente, à questão da existência de diferenças entre essa literatura e outras em língua alemã. Para elucidar os debates mais recentes, os contrastamos com argumentações representativas acerca da literatura austríaca das primeiras décadas do pósguerra. Ao comparar as diferentes abordagens, podemos perceber que a germanística austríaca atual deixou de se esforçar na construção de um "mito austríaco" e na procura do que seria a "essência" da literatura desse país. Passou da construção à análise do mito austríaco e do contexto sócio-histórico no qual se insere a produção literária da Áustria. Há diferenças argumentativas substanciais entre abordagens tradicionais com viés essencialista e as dos referidos teóricos. Ao mesmo tempo, é significativa a insistência por parte de germanistas e pensadores contemporâneos em se aceitar a existência (muitas vezes ignorada) de uma literatura austríaca cuja especificidade - resultante, sobretudo, de peculiaridades dos contextos históricopolíticos nos quais se inserem os escritores austríacos - não deve ser ignorada em pesquisas da área.

Palavras-chave: literatura austríaca - identidade austríaca - história da literatura 
Bohunovsky, R. - À procura da literatura austríaca

\section{Introdução: há uma literatura austríaca?}

Embora a questão da existência de uma literatura especificamente austríaca seja muitas vezes tida como "obsoleta" e, por essa razão, relegada ao total esquecimento ou dissolução de diferenças entre uma literatura alemã e uma austríaca, essa discussão pode causar certa "perturbação", como indica a epígrafe acima, da autoria de Wendelin Schmidt-Dengler, o mais conhecido e renomado germanista austríaco das últimas décadas. No Brasil, a omissão de eventuais diferenças parece ir mais longe - pelo menos em alguns momentos -, atingindo não apenas a produção literária do referido país”, mas o país como um todo. Para fins ilustrativos, cito um exemplo encontrado no contexto brasileiro: no Moderno Dicionário da Língua Portuguesa (1998), da editora Michaelis, podemos ver as seguintes definições do lexema "alemão":

alemão adj (lat alemanu) Concernente ou relativo à Alemanha. Pl: alemães. Fem: alemãa, alemoa. Sm 1 O natural da Alemanha. 2 Língua dos alemães. 3 gir Oponente, membro de grupo oposto ou rival.

Ao ler a definição de alemão como "língua dos alemães", causa estranheza a falta de referência aos outros países que têm o alemão como língua oficial. Surpreende o fato de que, ao mesmo tempo em que o dicionário exclui esses países e suas populações de fala alemã, ele inclui uma gíria muito pouco usada ${ }^{2}$.

O exemplo supracitado certamente não é representativo para discursos brasileiros sobre os países de língua alemã ${ }^{3}$. Mas, ele pode ser considerado sintomático de uma postura frequente, isto é, a tendência de incluir a pequena Áustria no vizinho maior e mais conhecido e a este atribuir a si seus produtos culturais. Não se trata aqui, porém, de uma exclusividade do Brasil, como mostra o renomado germanista austríaco Klaus Zeyringer na parte introdutória da sua obra de referência Österreichische Literatur seit 1945 (Literatura austríaca desde 1945). Nesse livro, o estudioso aponta

\footnotetext{
2 Outro exemplo, de teor anedótico: No dia 12 de fevereiro de 2010, o jornal paranaense Gazeta do Povo publicou uma resenha do filme A Fita Branca, que ganhou a Palma de Ouro de Melhor Filme no festival de Cannes em 2009. Seu diretor e roteirista, o austríaco Michael Haneke, é denominado "diretor alemão" no artigo (Gazeta do Povo, 12 de fevereiro de 2010, Caderno G: 4). Haneke nasceu em Munique. Sendo o autor do artigo um brasileiro, talvez tenha se confundido por estar acostumado com o jus solis adotado pelo Brasil. Isso, porém, não se aplica na Alemanha, nem na Áustria.

3 Nesse sentido, é importante também mencionar que, no Dicionário Houaiss da língua portuguesa (2001) e no Novo Aurélio (1999), as definições do lexema "alemão" são mais precisas e não deixam dúvida de que se referem à língua oficial não apenas da Alemanha, mas também da Áustria e da Suíça. Certamente, seria interessante analisar as abordagens críticas sobre a literatura austríaca também em trabalhos brasileiros voltados para a literatura em língua alemã. Como tal análise extrapolaria os limites e objetivos do presente trabalho, vamos deixá-la para um momento futuro.
} 


\section{Bohunovsky, R. - À procura da literatura austríaca}

vários exemplos de tentativas insustentáveis de "incorporação" da Áustria à "cultura alemã" por intelectuais, jornalistas e cientistas alemães (ZEYRINGER 2008: 24-26) nas últimas décadas. Zeyringer alega com toda razão que, enquanto outras literaturas não estariam confrontadas com a questão da legitimidade da sua existência, como a literatura argelina, a brasileira ou a própria alemã, a austríaca se encontraria, há décadas, na incômoda posição de ter de se indagar se o seu objeto de interesse realmente existe (ZEYRINGER 2008: 23).

Existe uma literatura austríaca? Em tempos de hibridização cultural e múltiplas identidades, de transnacionalidade e globalização, essa pergunta é um tanto suspeita de aludir a um nacionalismo ultrapassado, chauvinismo ou, na melhor das hipóteses, provincianismo. Como o adjetivo "alemão" é ambíguo - pode se referir tanto a algo concernente ao país Alemanha quanto à língua alemã -, a crítica literária prefere, muitas vezes, usar a expressão politicamente correta de uma "literatura em língua alemã", evitando assim a impressão de um possível "germanocentrismo". Porém, tal procedimento não evita, necessariamente, a homogeneização das diversas literaturas em língua alemã. Ao mesmo tempo, existem também estudiosos que fazem questão de usar a expressão "literatura alemã" para se referir a toda a produção literária escrita nessa língua, considerando desnecessária qualquer diferenciação entre as diversas literaturas nacionais e/ou regionais (p. ex. SCHLAFFER 2002).

Diante desse quadro, chamam a atenção diversas publicações recentes sobre a literatura austríaca escritas por renomados críticos literários e germanistas que defendem justamente a necessidade de se estudar e pesquisar a literatura desse país no seu contexto específico, levando em consideração aspectos e relações que a diferenciam de outras literaturas em língua alemã. São esses trabalhos que formam o ponto de partida do presente trabalho: Menasse (2005); Schmidt-Dengler (org.) (1995); Sebald (2006, 2004); Zeyringer (2008); Schmidt-Dengler (2010) ${ }^{4}$. Longe de procurar algo como a "essência" da literatura austríaca, qualquer coisa que pudesse caracterizar intrinsecamente obras literárias provenientes de autores austríacos ou uma definição de uma "literatura nacional" nos moldes do século XIX, as argumentações desses autores

4 Entre os autores aqui citados, Zeyringer e Schmidt-Dengler foram os que fizeram os estudos mais abrangentes e aprofundados sobre o tema ora tratado - o que justifica o enfoque especial dado às suas publicações neste trabalho. 


\section{Bohunovsky, R. - À procura da literatura austríaca}

apontam muito mais para as interdependências e correlações da literatura com contextos sócio-históricos singulares, com realidades extratextuais relevantes para a socialização de autores austríacos, mas muitas vezes negligenciadas quando se olha para a produção literária "em língua alemã" como um todo.

Assim, podemos observar que, ao mesmo tempo em que a literatura contemporânea ocupa frequentemente a função de ilustrar ou representar a desconstrução e/ou o questionamento de fronteiras e identidades ou culturais nacionais (mais ou menos) rígidas, ignorar tais fronteiras e as diferenciações que elas simbolizam pode levar a reações críticas e de protesto, principalmente da parte de minorias que se veem "incorporadas" num todo com o qual não se identificam na medida pressuposta pelos porta-vozes da inclusão.

Uma discussão sobre a literatura austríaca não pode ser feita sem se admitir o papel importante que a Alemanha ocupa inevitavelmente em qualquer debate desse teor, seja como fator de identificação, de estranhamento ou de diferenciação. Essa questão é abordada brevemente neste trabalho. Depois disso, procuramos expor, de maneira ilustrativa, aspectos sócio-históricos da Áustria que têm sido apontados, nos trabalhos críticos dos autores supracitados, como relevantes para os desdobramentos literários desse país depois de 1945: a difícil construção de uma identidade nacional, vinculada ao papel autoconferido de "vítima" do sistema nacional-socialista e a um espírito político extremamente conservador e tradicionalista, e o papel fundamental da Sozialpartnerschaft na vida política e cultural do referido país até, no mínimo, os anos 80. Não pretendemos oferecer, com tal seleção de tópicos, um quadro abrangente de todos os fatores que poderiam ser definidos como importantes para um estudo aprofundado da literatura austríaca e seu contexto sócio-histórico. Com os exemplos destacados neste trabalho, temos o objetivo de ilustrar o deslocamento do interesse principal da crítica que defende atualmente a especificidade da produção literária da Áustria, em comparação com abordagens mais tradicionais. Assim, esses exemplos ajudam a ilustrar que, mesmo em abordagens mais recentes sem foco essencialista, não se deixou de lado a defesa veemente da existência da uma literatura austríaca autônoma 5 .

5 É mister mencionar que literatura austríaca nem sempre é literatura em língua alemã. Além das línguas dos imigrantes das décadas mais recentes, há minorias autóctones cujas contribuições fazem da literatura austríaca uma literatura plurilíngue, como as minorias judias, eslovenas, croatas e húngaras. Por fugir do escopo 
Bohunovsky, R. - À procura da literatura austríaca

\section{2 Áustria e Alemanha - delimitações e incorporações}

"Nada estimula tanto o desejo de trabalhar com uma história da literatura austríaca como o fato de as histórias de literatura serem elaboradas na Alemanha, no caso concreto, na $\mathrm{RFA}^{6}$, e de procederem, em conformidade com esse fato, nas suas escolhas, sua periodização, caracterização e avaliação" (SCHMIDT-DENGLER; ZEYRINGER 1995: 14). Em 1995, num tom bastante indignado em relação a tal situação, Schmidt-Dengler e Zeyringer ainda consideravam uma história da literatura austríaca um "desiderato" (SCHMIDT-DENGLER; ZEYRINGER 1995: 13). Desde então, os nomes desses dois germanistas têm se tornado representativos para as tentativas de se diminuir tal lacuna. Em 1998, Zeyringer publica a primeira edição da sua Österreichische Literatur 1945-1998. Rapidamente esgotada a primeira, ele publica uma segunda edição (2001) e, em 2008, uma nova versão revisada e complementada, intitulada Österreichische Literatur seit 1945. A obra mais importante de Schmidt-Dengler, Bruchlinien, acaba de ser relançada (2010), menos de dois anos após o falecimento repentino do autor.

Numa das primeiras publicações à procura da literatura austríaca sem viés essencialista, a coletânea Literaturgeschichte: Österrich: Prolegomena und Fallstudien (História literária: Áustria: prolegômenos e estudos de caso), organizada por SchmidtDengler e outros (1995), Walter Weiss, um dos autores, polemiza ao resumir o que teria sido uma máxima influente desde Herder e os irmãos Grimm até a germanística de hoje: "Literatura em língua alemã é literatura alemã. Todas as especificidades devem, portanto, ser desprezadas" (WEISS 1995: 22). Schmidt-Dengler e Zeyringer se posicionam claramente contra essa "máxima", mas advertem que as polêmicas contra a praxe de incorporação da literatura austríaca pela alemã podem, por sua vez, gerar outro tipo de dependência (1995: 14). Embora Zeyringer afirme que, para que a "literatura austríaca não caia na vala comum alemã" (ZEYRINGER 2008: 15), a “questão principal” de todo germanista que se dedica à literatura austríaca contemporânea são os “Reviergrenzen" (limites de território), é importante ressaltar que existe um consenso,

do presente trabalho, não abordamos esse domínio da literatura da Áustria, mas indicamos a antologia Neue österreichische Lyrik und kein Wort Deutsch (Nitsche; Gitterle 2008) para um panorama representativo sobre a produção literária de poetas austríacos que não escrevem em alemão. 


\section{Bohunovsky, R. - À procura da literatura austríaca}

também entre os teóricos aqui abordados, de que não seria válido desconsiderar a literatura alemã como constitutiva para a austríaca.

Há inúmeros exemplos de trabalhos críticos e histórias da literatura em língua alemã que associam a literatura austríaca com a Alemanha, sem maiores explicações ou justificativas. Zeyringer pergunta, por exemplo, por que, num livro intitulado Deutschland erzählt - von Rilke bis Handke (A Alemanha conta - de Rilke até Handke), os textos dos dois autores mencionados no título seriam provenientes da Alemanha (ZEYRINGER 2008: 24). Ou, por que, nas coletâneas organizadas por Marcel ReichRanicki, com os títulos “de Arthur Schnitzler até Robert Musil” e “de Joseph Roth até Hermann Burger", se trataria de Deutsche Erzähler des 20. Jahrhunderts (Narradores alemães do século XX) (ZEYRINGER, 2008: 24). Além de vários outros exemplos de publicações nas quais autores austríacos são apresentados como alemães, Zeyringer cita também um estudo de Gabriele Holzer, pesquisadora que aponta para a relação entre a ideia da "nação de cultura alemã" e a suposta "incapacidade" dos alemães de "entender os austríacos como não-alemães" e que se declara "desconfiada" em relação a tentativas de "desnacionalização" da literatura quando tais movimentos são impostos a nações menores (HOLZER 1995 apud ZEYRINGER 2008: 25) ${ }^{7}$. É mister mencionar aqui ainda a seguinte observação crítica de Schmidt-Dengler: "No que diz respeito à literatura austríaca em histórias de literatura alemãs (Hanser, Rowohlt, Reclam, UTB), sinto falta, não raramente, da sensibilidade justa que existia em relação à RDA ${ }^{8}$ " (SCHMIDTDENGLER 2010: 18).

Diante desse quadro, é interessante fazer uma pequena referência ao livro Die kurze Geschichte der deutschen Literatur (A curta história da literatura alemã), de Heinz Schlaffer (2008). O estudioso responde afirmativamente à pergunta se existe "uma história singular da literatura alemã" (SCHLAFFER 2008: 10) e argumenta que há uma "unidade interna" nessa literatura, produzida "pela [sua] relação alternante, mas nunca indiferente" frente à "religião cristã, sobretudo suas vertentes místicas, protestantes e pietistas" (SCHLAFFER 2008: 20). Diante dessa linha de argumentação -

\footnotetext{
7 No referido livro de Zeyringer (2008), consta uma lista abrangente de comentários e argumentações mais extensas de escritores e jornalistas alemães que questionam ou negam a pertinência de qualquer tipo de consideração sobre a especificidade do contexto sociocultural-histórico da Áustria em discussões acerca da história literária da língua alemã. Referindo-se a um estudo de Holzer (1995), Zeyringer lista nomes como Sigmund Freud, Peter Handke, Fritz Lang, Robert Musil, Franz Kafka, Franz Werfel, Arnold Schönberg, Karl Kraus, Otto Weininger, Norbert Gstrein e Romy Schneider, que em diversos momentos teriam sido "naturalizados" alemães (Zeyringer 2008: 25). 


\section{Bohunovsky, R. - À procura da literatura austríaca}

embora, sem dúvida, elucidativa no que diz respeito a uma parte da literatura "em língua alemã” -, a produção literária proveniente dos países (católicos!) do império austrohúngaro é atribuída de antemão à literatura "alemã" - o que significa, consequentemente, que é avaliada e discutida a partir dos critérios definidos como relevantes para a produção literária das regiões majoritariamente protestantes ${ }^{9}$. Assim, de acordo com Schlaffer, a "literatura alemã" teria sido "assunto do norte protestante" até o século XX, quando duas cidades católicas, "que não ocuparam nenhum papel importante na história da literatura alemã até o século XIX: Viena e Praga" (SCHLAFFER 2008: 134), finalmente, ganhariam algum destaque. Partindo desse raciocínio, será difícil para as literaturas austríaca e suíça, por exemplo, não perderem seu papel de periféricas, já que teriam de determinar sua posição sempre em relação ao país que, usando as palavras de Zeyringer, detivesse o "poder de definição" e dependeriam do “tapinha nas costas” desse poder (ZEYRINGER 2008: 24).

Schlaffer comenta com certa ironia sobre a tendência, nos últimos anos, "de se olhar para a literatura suíça, a austríaca e, pasme, até a literatura do Tirol do Sul ${ }^{10}$, como territórios (sic) independentes", e da exigência de se observar como sendo um "conceito generalizante" o de uma "literatura de língua alemã" (SCHLAFFER 2008: 12). Como os vários autores citados por Zeyringer, Schlaffer repete o movimento de partir da socialização histórico-política alemã e inclui a Áustria e a Suíça no conceito de uma “literatura alemã". Desse modo, essas literaturas não deixam o lugar de apêndice, sendo consideradas como "exceções amáveis de uma norma" (ZEYRINGER 2008: 29). Não é de se admirar o fato de serem geralmente germanistas austríacos e suíços os que apontam para a existência de distintivos entre a literatura alemã e aquelas dos seus respectivos países. Na Suíça, já em 1970, o germanista suíço Max Wehrli questionou, por exemplo, se haveria uma história da literatura "alemã" (1970). O escritor e germanista alemão W.G. Sebald é uma exceção nesse cenário, pois são de sua autoria duas coletâneas de ensaios sobre a literatura austríaca $(2004 ; 2006)$, nas quais procura analisar algumas das "relações complexas" que lhe parecem ser "constitutivas" para a literatura austríaca (2006: 9).

9 É mister lembrar que a Alemanha também tem uma expressiva população católica, especialmente na Baviera, mas também em outras regiões. 10 Tirol do Sul é uma província italiana, onde a maioria da população fala o alemão como primeira língua. 


\section{Bohunovsky, R. - À procura da literatura austríaca}

Uma problemática concreta do alinhamento da literatura austríaca pela literatura alemã é a periodização, como apontam Schmidt-Dengler e Zeyringer: "As cesuras temporais não podem simplesmente ser vertidas da historiografia literária alemã para a Áustria, já que as condições, as estruturas e os entrelaçamentos do 'lugar histórico' da literatura austríaca são claramente diferentes" (1995: 16). Os referidos estudiosos apontam que o período literário do Sturm und Drang assim como o naturalismo não têm muita relevância na Áustria (cf., por exemplo, 1995: 16). Em outros momentos, a literatura austríaca se manifestou de forma incomparável: na "Biedermeierzeit", na "Jahrhundertwende" (virada do século) ou na época do "Volkstheater" (teatro popular) (WEISS 1995: 25-26). Uma continuidade temática relevante na literatura austríaca é o "mito habsburgo" (MAGRIs 2000), destacado, por exemplo, por Thomas Bernhard, que declara a história do império dos habsburgos como responsável pela mistura de "amor e ódio" que ele sente pela Áustria e que seria, por sua vez, "a chave para tudo que [ele] escrev[e]” (BERNHARD 1983 apud ZEYRINGER 2008: 27). Referindo-se mais especificamente às condições históricas de produção e recepção, Schmidt-Dengler ressalta que "a história austríaca na sua especificidade é claramente distinguível da alemã, sobretudo desde 1806" e ilustra essa afirmação com a listagem das datas "1866, 1914, 1918, 1933, 1934, 1945 e 1955", que ocupam "para a história da mentalidade e da literatura austríaca uma função bem diferente dessas mesmas datas para a história alemã" (SCHMIDT-DENGLER 2010: 16).

O campo do trabalho científico que se dedica especificamente à "literatura austríaca" é a história literária dedicada à produção e recepção de textos literários num âmbito social, político e histórico concreto, uma história social da literatura. Como ressaltam Schmidt-Dengler e Zeyringer: "quem sabe acerca das interações de natureza social e política nas quais os autores austríacos estão inseridos, deve saber também que é justamente nesse campo que as diferenças podem ser mostradas” (SCHMIDT-DENGLER; ZEYRINGER 1995: 15). Weiss resume de maneira semelhante:

\footnotetext{
A fusão - comum na germanística de hoje - de língua e nação estorva ou até impede uma aproximação com a literatura austríaca que leve a sério os aspectos históricos e cultural-históricos constitutivos de uma maneira adequada. A literatura austríaca não pode ser definida por meio de uma dicotomia de línguas, língua austríaca vs. língua alemã. Ela também não pode ser incorporada, de
} 


\section{Bohunovsky, R. - À procura da literatura austríaca}

modo linguocentrista, como "literatura alemã". [... $]^{11}$ Além disso, as especificidades austríacas devem ser consideradas também em obras literárias escritas em outras línguas que não o alemão, e não apenas nas do período da "grande Áustria", da monarquia dos Habsburgos, mas também naquelas da literatura da Segunda República. (WEISS 1995: 24) ${ }^{12}$.

\section{A literatura a serviço da restauração nacional}

As histórias nacionais da Áustria e da Alemanha divergem muito. Entendemos a Alemanha, no sentido de Jürgen Habermas (1999), como um país que se desenvolveu da "nação" - uma comunidade linguística, cultural, histórica e/ou política - para o "Estado" - entendido como conceito jurídico. Em contrapartida, a Áustria nas suas fronteiras atuais tornou-se primeiro um Estado. Fazer dele uma nação tornou-se uma necessidade política, para satisfazer as exigências dos aliados que, durante os primeiros dez anos depois da Segunda Guerra Mundial, ocuparam o país. Só mais tarde, décadas depois da fundação da Segunda República, a população começou a entender a Áustria como uma nação. De acordo com Menasse, a insistência política do pós-guerra de fazer referência a uma suposta "grande história austríaca", em combinação com a falta de qualquer debate sobre "as continuidades pessoais e estruturais do tempo nazista", "funcionou" (MENASSE 2005: 39). Atualmente, mais ou menos 90 por cento da população concordaria com a afirmação de a Áustria ser uma "nação" (MENASSE 2005: 39).

A época da Primeira República (1918 até 1934) foi marcada por uma enorme desconfiança e descrença na condição de sobrevivência da pequena república que tinha restado do grande império austro-húngaro. A "Rede über Österreich" (discurso sobre a Áustria), de Anton Wildgans (1930) - que, na época, causou muita reação e discussão -, foi uma das primeiras tentativas de criar um imaginário positivo acerca daquilo que seria a Áustria e o austríaco. É interessante notar que, embora ressaltando o papel político central da minoria "alemã", Wildgans define a "multiplicidade dos povos" que a Áustria herdou do império austro-húngaro e a suposta "humanidade" do seu povo como fundamentos do seu caráter, em clara distinção em relação aos "germanos"

11 Weiss cita Frank Kafka, Franz Werfel, Elias Canetti, Paul Celan e Franz Csokor como autores em cujas obras a "diferenciação entre a língua nacional alemã e o alemão da monarquia (reformada)" seria "especialmente razoável" (Weiss, 1995: 24).

12 Esta tradução, assim como todas as outras de livros não traduzidos para o português, é nossa. 
Bohunovsky, R. - À procura da literatura austríaca

(WILDGANS 1930) - interpretação que se evidenciou exageradamente otimista. Mais tarde, depois da catástrofe da guerra e no contexto da procura de uma possível identidade austríaca positiva, Heimito von Doderer, no seu grande romance Die Strudelhofstiege (A escadaria de Strudelhof ${ }^{13}$ ) (primeira publicação em 1966), situado nos anos após a Primeira Guerra Mundial, retoma esse imaginário multicultural da Áustria no qual o país procurava enraizar sua "nova" identidade oficial depois da Segunda Guerra Mundial. Vinculado explicitamente a um distanciamento em relação aos alemães, esse imaginário aparece já na primeira página do referido romance, quando se introduz o personagem Doktor Negria no contexto das nacionalidades que outrora tinham composto o império austro-húngaro:

Desde sempre havia esses romenos e búlgaros em Viena, geralmente no circuito da universidade ou da academia de música. Estava-se acostumado com eles: com seu jeito de falar, que se impunha cada vez mais junto com o austríaco, seus remoinhos de cabelo grosso acima da testa [...]. Sem dúvida, continuavam a ser estrangeiros (esses que recebiam constantemente pacotes enormes com as suas delícias nacionais), porém não tão consolidadamente estrangeiros como os alemães do norte [...] (DODERER 1977: 9).

A constante descrença numa nação austríaca - entre outros fatores, apontada como responsável pelo surgimento do austro-fascismo e do entusiasmo popular pela anexação ao Deutsches Reich em 1938 - continuou depois de 1945. Ainda em 1956 (depois de mais de dez anos de propaganda pró-nação-austríaca!), a "nação alemã" parecia mais atraente como elemento identificador: nesse ano, $46 \%$ da população se entendeu como pertencente ao "povo alemão" (MENASSE 2005: 37).

Os esforços políticos - exigidos e apoiados pelos aliados - para construir um Estado nacional viável e uma genuína "identidade austríaca" depois de 1945 se basearam, sobretudo, numa defesa da Áustria como a primeira "vítima" do nacionalsocialismo. Assim, atou-se a suposta identidade austríaca aos tempos pré-nazistas (sobretudo ao século XIX), evitando-se um debate crítico sobre a participação da própria população no Terceiro Reich. De acordo com Zeyringer,

[d]iferentemente de outros lugares, diferentemente da RFA, uma ideologia austríaca oficial construiu os fundamentos do Estado sobre a "declaração de

13 Nome de uma escadaria estilo art nouveau, em Viena. 
Bohunovsky, R. - À procura da literatura austríaca

Moscou"14 de 1943, sobre o amplo recalcamento do tempo nazista e da adaptação católico-fascista do Ständestaat ${ }^{15}$ e, também, sobre a assim chamada "continuidade", uma tradição retrógrada austríaca. (ZEYRINGER 2008: 30).

Schmidt-Dengler prefere uma argumentação mais cautelosa e não concorda com a ênfase dada pela pesquisa na suposta "continuidade sem nenhuma ruptura" (SCHMIDTDENGLER 2010: 26). Ele destaca que, depois de 1945, a maioria dos escritores teria se distanciado da ideologia nazista, porém - e Schmidt-Dengler faz questão de ressaltar que tal fato seria de suma importância para ele - não se distanciaram daquilo que era "o nazista dentro de si: a relação com a própria postura foi marginalizada" (SCHMIDTDENGLER 2010: 26). Essa interpretação não diverge muito daquela de Menasse (2005), que denomina a Áustria o país do "Entweder-und-oder" (ou-e-ou), onde posturas conflitantes não se excluem, mas conseguem achar um modus vivendi.

Como destacam os autores nos quais este trabalho está fundamentado, o referido contexto político depois de 1945 teve reflexos na literatura, devido primordialmente a um amplo entrelaçamento entre política cultural - cujo objetivo principal era a construção de uma "identidade austríaca" positiva baseada em "valores eternos" (ZEYRINGER 2009: 88) de uma suposta cultura nacional - e a produção literária. A "reconstrução" do país e de uma identidade nacional trouxe consigo uma "reconstrução" de uma literatura tradicionalista (ZEYRINGER 2009: 88). Diferentemente da Alemanha onde o Gruppe 47 (Grupo 47) marcou uma ruptura e uma crítica radical da ideologia nazista e seus resíduos na sociedade pós-guerra -, na Áustria daquela época, não houve uma ruptura radical, nem com o fascismo, nem com o fascismo doméstico, o austrofascismo (1934-1938). O domínio literário foi marcado por uma continuidade ideológica cujo objetivo era o apagamento da diferença, e autores que se opunham a essa situação foram ignorados, decidiram emigrar ou, como Jean Améry, se negaram a voltar a viver no seu país de origem. Como aponta Zeyringer, depois da guerra, muitos funcionários da época do austro-fascismo voltaram a posições-chave da vida cultural do país (ZEYRINGER 2008: 53). O escritor Alexander Lernet-Holenia disse, ainda em 1945, a frase que resume a tendência restaurativa e a falta de vontade de uma postura mais autocrítica que vingaram até os anos 60: "De fato, só precisamos continuar onde fomos

\footnotetext{
14 Trata-se de uma declaração dos aliados de que poderiam reconhecer a Áustria como a primeira "vítima" da Alemanha nazista, caso o país colaborasse para a sua "liberação". Essa "teoria de vítima" só foi colocada em discussão pública em ocasião do "caso Waldheim”, em 1986. 15 Sistema político autoritário, também denominado de austro-fascismo, de 1933/34 até 1938.
} 


\section{Bohunovsky, R. - À procura da literatura austríaca}

interrompidos pelos sonhos de um louco" (LERNET-HOLENIA 1945 apud ZEYRINGER 2008: 53).

O percurso pessoal e literário de Lernet-Holenia é, aliás, sintomático da restauração da vida cultural da época. Em 1942, ainda como membro da Reichsschrifttum-Kammer (câmera imperital dos escritores) ${ }^{16}$, o autor deu a ideia para o filme Die große Liebe (O grande amor), com Zarah Leander, filme comercial que enaltece os preceitos nazistas e que teve sucesso estrondoso naquela época. Depois da guerra, Lernet-Holenia tornou-se um símbolo da continuidade austríaca na vida social e política. Para tal representação simbólica contribuiu o fato de que ele "não só "tinha visto' o imperador", mas talvez pudesse ser um filho ilegítimo dele (MENASSE 2005: 139). Como era politicamente imprescindível ter fama de antifascista depois de 1945 uma "necessidade política perante os aliados", mas não necessariamente para a nova “identidade austríaca” interna (MENASSE 2005: 20-21) -, Lernet-Holenia beneficiou-se do fato de seu romance Mars im Widder (Marte em Áries), uma "recusa nobremente cifrada a Hitler", ter sido proibido pelos nazistas em 1940 (MENASSE 2005: 139). Em 1969, renunciou de sua função como presidente do P.E.N. Club austríaco como forma de protesto contra o Prêmio Nobel concedido a Heinrich Böll que, para Lernet-Holenia, teria sido por demais comprometido com vertentes políticas da esquerda. Com raízes claramente comprometidas com a ideologia nazista, mas mesmo assim com a fama oficial de antifascista, Lernet-Holenia pode assim ser citado aqui como mais um exemplo da Áustria pós-guerra, o "Land des Entweder-und-oder" (MENASSE 2005: 36).

Podemos citar ainda alguns outros exemplos que ilustram a falta de uma ruptura clara com a ideologia nazista: uma palestra de Karl Heinrich Waggerl - um dos autores mais lidos e reconhecidos na Áustria ainda em 1972 e, bem antes disso, um dos escritores preferidos pelo sistema nazista - com o título "Elogio à pátria", que corresponde a uma outra declaração dele, publicada em 1939 na revista Ewiges Deutschland (Eterna Alemanha) (ZEYRINGER 2008: 54). Em 1964, um discurso de Thomas Bernhard foi introduzido por Hermann Stuppäck, outrora Gaukulturhauptstellenleiter, alto funcionário nazista (ZEYRINGER 2008: 61). Ainda em 1992, alguns políticos importantes do país participaram como convidados honoríficos de um encontro da "Kameradschaft IV/Waffen-SS", enquanto nenhum político austríaco

16 Uma das principais organizações criadas a partir do Reichskulturkammergesetz (Lei Câmara Imperial de Cultura) que centralizou e fortaleceu o domínio dos nacional-socialistas na área de cultura. 


\title{
Bohunovsky, R. - À procura da literatura austríaca
}

esteve presente numa homenagem à liberação do campo de concentração Mauthausen (MENASSE 2005: 109) ${ }^{17}$. O cânone literário se constituiu até os anos 70 pela "literatura dos Reichsverweser" - com uma tendência claramente "völkisch" (nacionalista e de acordo com as premissas ideológicas do nazismo) e uma forte propensão anticomunista. São autores representativos dessa época: Bruno Brehm, Max Mell e Karl Heinz Waggerl (ZEYRINGER 2009: 88). Nas suas obras, manifesta-se uma glorificação da Heimat (pátria), da natureza e da paisagem como, por exemplo, no conto "Fröhliche Armut" (Pobreza feliz), de Waggerl (1986). Autores críticos da "primeira geração" como Ilse Aichinger - Die größere Hoffnung (A esperança maior) (1948) - pertenciam, nas palavras de Zeyringer, à "modernidade rejeitada" (2009: 93) no próprio país, mesmo quando reconhecidos fora dele. Paula Ludwig, que voltou do exílio brasileiro em 1953, deixou a Áustria novamente em 1956, devido à "atmosfera política insuportável" (ZEYRINGER 2009: 95) e se instalou em Wetzlar.

Numa entrevista recente para um jornal austríaco, o ex-diretor do Burgtheater (teatro nacional austríaco) em Viena, o alemão Achim Benning, lembra da impressão que teve da capital austríaca quando lá chegou poucos anos depois do fim da guerra, como estudante de filosofia, germanística e história, reforçando a situação do "horrível ar misturado" ("grausliche Mischluft") que reinava na cidade - e que de acordo com Benning ainda a marca:

\begin{abstract}
Para mim, algo era absolutamente incompreensível: que os velhos nazistas trabalhassem na maior harmonia com aqueles que tinham acabado de voltar do exílio. Eles estavam sentados juntos na dramaturgia vienense e se davam as mãos. Hans Niederführ, que tinha notificado em Berlim a "Entjudung" do seminário Reinhardt em 1938, de repente se apresentou como papa de Reinhardt. (FREITAG 2010: 3).
\end{abstract}

Não houve mudanças radicais nesse "novo" começo. De acordo com Menasse, "houve figuras como Lernet-Holenia [...], mas nem de longe houve um debate literário adequado do fascismo e da guerra", ou seja, "a Áustria não produziu nenhum Borchert, nem um Grupo 47"” (MENASSE 2005: 40). Muito pelo contrário, “os arquitetos da Áustria viam a literatura como base fundamental da identidade austríaca”, cuja função

17 Poucas semanas antes do fim da guerra, 500 presos que tinham conseguido fugir do campo de concentração de Mauthausen foram assassinados, com pouquíssimas exceções, pela população local. Nenhum dos que participaram desse crime - que ganhou o nome de "Mühlviertler Hasenjagd" - foi jamais processado ou punido. 
Bohunovsky, R. - À procura da literatura austríaca

seria "lembrar" o leitor da "grande herança" que tinha sido interrompida pela “catástrofe” da qual o país teria sido "vítima” (ZEYRINGER 2008: 55).

Nesse processo, o P.E.N. austríaco ocupou um papel central. Fundado em 1924, teve Arthur Schnitzler como seu primeiro presidente. Proibido na Áustria durante o período nazista, foi mantido em Londres pelos exilados. Em 1947, a associação foi reconstituída com uma condição fundamental para ser aceita pelo P.E.N. internacional, a de firmar um compromisso antinazista. Aos poucos, no entanto, foi incorporando autores outrora völkisch, isto é, comprometidos com o sistema nazista, como Franz Nabel, Max Mell e Friedrich Schreyvogel (ZEYRINGER 2008: 77). O grande poder político do P.E.N. e sua posição política e estética conservadora explicam em boa parte a estagnação da vida literária austríaca nas primeiras décadas pós-guerra.

Autores jovens que não se encaixavam no perfil desejado pelo P.E.N. austríaco foram taxados de provocadores e procuraram respaldo em âmbitos mais favoráveis à literatura progressiva. Antes que tal acontecesse na Áustria, Ingrid Bachmann e Ilse Aichinger tiveram sucesso no Gruppe 47. Nessa época, estabeleceu-se o termo Nestbeschmutzer (alguém que suja o próprio ninho), usado em anos mais recentes por representantes políticos da direita em relação a autores como Thomas Bernhard, Elfriede Jelinek etc. Enquanto na Áustria reinava o "culturalismo representativo" com autores pouco considerados fora do país (com a exceção de Heimito von Doderer, ${ }^{18}$ que ocupava uma posição entre os dois extremos), os trabalhos que iniciaram uma ruptura de tradição - de Aichinger, Bachmann, Celan, Canetti, Fried etc. - foram lidos predominantemente na Alemanha (ZEYRINGER 2008: 95). Apenas nos anos 60 iniciouse um processo de abertura na Áustria; assim, em 1968, Bachmann recebeu o Österreichischer Staatspreis für Literatur (Prêmio Nacional Austríaco de Literatura).

Como evidencia o estudo de Zeyringer sobre diversos grupos de interesses e associações de autores na Áustria pós-guerra (Zeyringer 2008: 75 - 86), o P.E.N. dominou a vida literária durante muitas décadas e se esforçou na construção do "mito austríaco", mesmo depois do advento de outras organizações representativas de escritores. A produção literária do Wiener Gruppe (Grupo de Viena) ${ }^{19}$ a partir de meados dos anos 50 - que, pela primeira vez, focou questões estéticas de literatura e se

18 Die Studelhofstiege (1966) e Die Dämonen (1956) foram seus romances mais conhecidos.

19A Wiener Gruppe (Friedrich Achleitner, H. C. Artmann, Konrad Bayer, Gerhard Rühm, Oswald Wiener) se manifestou, pela primeira vez, em 1957 com esse nome. Influenciada por técnicas do surrealismo e do dadaísmo, marcou de maneira douradora a vanguarda literária da Áustria. 


\section{Bohunovsky, R. - À procura da literatura austríaca}

mostrou absolutamente incompatível com a visão conservadora do estabelishment - foi ignorada ou chamada de Schmutz und Schund (literatura suja e sem valor) e entartet (degenerada). Vários dos seus membros deixaram o país, frustrados com as extremas dificuldades de alcançar um certo grau de publicidade e reconhecimento. Grupos mais formalizados - como a Forum Stadtpark em Graz (1959/1960) e, mais tarde, a Grazer Autorenversammlung $(G A V)(1973)$ - se definiam muito mais pela sua oposição ao P.E.N. do que através de critérios estéticos. Tal situação foi considerada uma "vergonha para o P.E.N. internacional e uma vergonha para a Áustria” por Ernst Jandl (apud ZEYRINGER 2009: 81). Mais tarde, o espírito conciliador da Sozialpartnerschaft invadiu também a GAV, que "sofreu uma repreensão por mostrar uma grande disposição para compromissos e falta de conteúdo" (ZEYRINGER 2009: 84). Não podemos esquecer também o boicote a Bertolt Brecht (Brecht-Boykott), entre 1952 e 1963, pelos teatros vienenses, fato bastante elucidativo para se entender o âmbito cultural do país naqueles anos.

\section{A Sozialpartnerschaft $e$ a tendência conciliadora na política $e$ na literatura}

A continuidade política e ideológica em amplos domínios da vida cultural da Áustria pode ser mais bem entendida se a relacionamos com outra peculiaridade desse país. Trata-se da Sozialpartnerschaft (parceria social), uma instituição políticoeconômica informal que marcou profundamente a vida política austríaca na segunda metade do século XX. Na sua forma austríaca, entende-se por Sozialpartnerschaft uma parceria de caráter informal, não público, de grupos representativos da sociedade (grandes partidos políticos, indústria, sindicatos) cujo objetivo é a formação de consenso, evitando debates políticos públicos, conflitos abertos entre os diferentes grupos influentes, assim como greves, manifestações etc. De fato, as reuniões e decisões tomadas atrás de portas fechadas pelos representantes da Sozialpartnerschaft levaram a uma perda de relevância da vida política e de debates públicos e até, para usar as palavras polêmicas e provocativas de Menasse, a uma "falta de função" do parlamento (MENASSE 2005: 195). 
Bohunovsky, R. - À procura da literatura austríaca

No artigo "Die Herausbildung sozialpartnerschaftlich-ästhetischer Strukturen in der österreichischen Literatur der Zweiten Republik" (A formação de estruturas estéticas baseadas na Sozialpartnerschaft da literatura austríaca durante a Segunda República), que consta na coletânea Das war Österreich (Isso era a Áustria) (2005), Menasse levanta a tese de que a influência da "alma da Sozialpartnerschaft" não pode ser limitada ao desenvolvimento político e econômico do país, pois marcou também "as estruturas da vida literária e imprimiu sucessivas marcas estéticas que caracterizam substancialmente a literatura austríaca e fundamentam também o seu significado e o seu sucesso" (MenAsse 2005: 173). Sem se aprofundar tanto como Menasse, Zeyringer também argumenta no sentido da "Sozialpartnerschaft no âmbito literário" (ZEYRINGER 2008: 83) e destaca a relação entre o "espírito tradicionalista da Sozialpartnerschaft" e a impossibilidade de surgir, na Áustria, um poesia engajada sócio-politicamente como aquela de Bertolt Brecht ou Hans-Magnus Enzensberger, na Alemanha (ZEYRINGER 2008: 100).

Menasse não é o primeiro a constatar a tendência à conciliação e ao antirradicalismo na sociedade e na literatura austríaca. Joseph P. Strelka, na sua procura pela "essência austríaca na literatura", vê na Idade Média, concretamente na poesia de Walter von der Vogelweide, os inícios mais remotos da "tendência" supostamente austríaca "à mistura e à conciliação", assim como "a inclinação à moderação e à consciência da tradição, a relativização ou transcendência da realidade para o sonho, o inconsciente, o além" (STRELKA 1994: 8). Nos anos 50, num ensaio representativo da procura de uma "identidade nacional", Friedrich Heer define a "Humanitas Austríaca" como a "capacidade formada ao longo da história para a reconciliação dos opostos, para a sustentação de um meio-termo entre os extremos, de uma tolerância das diferenças drásticas" (JoHNSTON 2010: 279). Já na sua Rede über Österreich, Wildgans frisa o suposto dom dos austríacos de saberem se colocar na posição dos outros, de entenderem "outros mundos emocionais nacionais, outras almas nacionais" e de não serem "Herrenmenschen" (dominadores) (1930), em clara distinção dos alemães.

Wildgans, Heer e Strelka, na tradição essencialista das discussões em torno do “caráter" austríaco, atribuem a tendência à conciliação exatamente a tal "caráter" inato e com supostas raízes genéticas em tempos remotos. Nos estudos mais recentes aos quais o presente artigo faz referência, a abordagem é outra. Menasse, por exemplo, não deixa de destacar a busca de evitar conflitos abertos como um ponto central na sociedade e 
Bohunovsky, R. - À procura da literatura austríaca

literatura desse país, relacionando-a, no entanto, com constelações político-históricas concretas e não com o "caráter" do "povo austríaco". Mesmo assim, ainda de acordo com Menasse, o movimento de considerar a procura por harmonia e a atuação como “cadinho" dos opostos como algo "tipicamente austríaco" remonta à época do império austro-húngaro dos habsburgos (MENASSE 2005). Desde então, tal movimento teria se manifestado como topos literário de uma relação peculiar entre mestre e servo (Herr und Diener), uma relação "marcada pela dependência mútua", cuja "estabilidade tem se tornado o centro da atuação social e individual" (MENASSE 2005: 179). De acordo com Menasse, o referido topos é a "única continuidade de tradição literária relevante entre a monarquia dos Habsburgos e a Segunda República" (MENASSE, 2005: 184) e se revelou como absolutamente compatível com a "estética da Sozialpartnerschaft" (MENASSE 2005: 184). Menasse identifica também em obras de Thomas Bernhard e Peter Handke o topos do mestre/servo como um "princípio criador": em Frost, da autoria de Bernhard (1963) e em Publikumsbeschimpfungen (1965) (Insulto ao público), de Handke. Assim, na "Geständnisprosa" (prosa de confissão) de Bernhard, Menasse observa que, "através das confissões, os conflitos e diferenças somem e os protagonistas coincidem no primeiro plano, a saber, na relação comunicativa" (MENASSE 2005: 188). Parece-nos mister destacar que aquilo que outrora tinha sido visto como "identidade nacional" ou "característica" de um povo é reinterpretado aqui como topos literário ${ }^{20}$.

Menasse ainda enxerga outra relação entre a Sozialpartnerschaft e a literatura, além da força do topos literário: um suposto caráter conciliador:

[O] espírito da Sozialpartnerschaft disseminou concepções de harmonia de caráter predominantemente não-público, antidemocrático no Überbau [superestrutura] da sociedade. Essa estrutura antidemocrática, não-pública, no Überbau austríaco [...] implicou, para a literatura austríaca, não apenas uma despolitização, isto é, um conservadorismo explícito, mas se manifestou também numa apoteose do eu, que se tornou uma característica estrutural estética da literatura austríaca e, sob o conceito de "Innerlichkeit" [interioridade], um ícone literário. (MENASSE 2005: 195).

\footnotetext{
20 Já Johnston, na sua obra mais recente, lamenta que, "na pós-modernidade, os historiadores culturais têm marcado uma terminologia para evitar qualquer caracterização generalizante de povos, tribos e culturas" (Johnston 2010: 282) e opina que "a pesquisa sobre a longa duração da cultura austríaca [...] só se tornará viável novamente quando receber uma terminologia adequada, na qual o conceito do habitus, de Norbert Elias, deverá ocupar um papel central” (Johnston 2010: 283). Convém ressaltar o fato de que essa interpretação em defesa de uma "cultura nacional" venha justamente de um autor australiano - aparentemente menos preocupado com as implicações políticas e as críticas que tal visão poderia levantar num mundo marcado tanto por vertentes xenófobas e nacionalistas quanto pela desconstrução de fronteiras reais e simbólicas.
} 


\section{Bohunovsky, R. - À procura da literatura austríaca}

A "opacidade e o anonimato da estrutura de atuação política" (MENASSE 2005: 195) teria beneficiado a "retirada" dos escritores para seu mundo interior. Obviamente, Menasse sabe que a "Innerlichkeit" na literatura não é um fenômeno apenas da literatura austríaca. Porém, faz questão de ressaltar as diferenças entre os dois tipos de "Innerlichkeit" que podem ser observados na literatura de língua alemã: de acordo com o ensaísta, na Alemanha, a vertente denominada de "Neue Innerlichkeit" teria sido uma "expressão assustada de indivíduos" ao desenvolvimento de um "Estado forte" - "que não se caracterizou, como aconteceu na Áustria, por um alto grau de harmonização institucionalizada de conflitos, mas, pelo contrário, por uma agressividade aberta no processo de lidar com conflitos (Menasse 2005: 196). No entender de Menasse, o fato de a "tendência para a Innerlichkeit" ter sido consequência de "um desdobramento generalizante da sociedade" explicaria também por que os "princípios de forma e estilo dessa vertente na Alemanha foram preconcebidos por escritores austríacos" (MENASSE 2005: 196). Além disso, a literatura associada à "Neue Innerlichkeit", na Alemanha, teria sido "uma das muitas tendências e concepções literárias" (MENASSE 2005: 196), ao lado, por exemplo, da literatura "do mundo trabalhista" - vertente praticamente inexistente na Áustria. Nesse país, destaca-se uma literatura que não se interessa por acontecimentos históricos reais, mas se constrói num "metatempo a-histórico", como os romances de Thomas Bernhard (cf., por exemplo, MENASSE 2005: 199). A aversão à política real de Bernhard e dos protagonistas de seus livros encontramos também em Handke e seu "solipsismo político" que, para Sebald, remonta à "longa tradição da impossibilidade de uma existência política na Áustria” (SEBALD 2006: 104). Numa coletânea de jovens autores austríacos, os organizadores atribuem à Innerlichkeit uma postura política, mesmo que implícita: os autores austríacos se diferenciariam dos seus colegas alemães na sua "consciência e crítica linguística" e estariam "interessados na língua e na forma, ousados, provocativos, rigorosos, excêntricos, lúdicos e na sua insistência na tematização dos sentimentos e sonhos pessoais, afinal de contas também políticos, sem nunca elevar a política ao seu tema explícito" (FLEISCHANDERL; ERNST 2003: 7).

No início dos anos 60, uma literatura progressista começou - aos poucos - a se impor contra a literatura tradicionalista. A prática de recalcamento (Verdrängung) tornou-se então alvo de crítica e topos literário, como, por exemplo, na literatura de Ingeborg Bachmann, Thomas Bernhard ou Gerhard Fritsch. Em 1961, foi publicado o 
Bohunovsky, R. - À procura da literatura austríaca

livro de prosa Das dreißigste Jahr (O trigésimo ano), de Bachmann. O conto "Unter Mördern und Irren" (Entre assassinos e loucos) deu início àquilo que se tornou a "melodia literária" (ZEYRINGER 2008: 103): o debate crítico com a "topografia" nazista, a continuação de estruturas totalitárias na sociedade, a crítica ao conceito de Heimat defendida pelo establishment literário da época (cf. também SCHMIDT-DENGLER 2010: 206). O "caso Waldheim", em 1986, iniciou uma nova fase de literatura dessa vertente, colocando em evidência que os discursos da "ideologia reacionária da paisagem" (SEBALD 2004), muitas vezes vinculados ao “deutsches Wesen” (caráter alemão), ainda existiam e continuam existindo (cf. também SCHMIDT- DENGLER 2010: 26).

Vale ainda lembrar que em todos os estudos e ensaios aqui citados, o papel do conceito de Heimat é destacado como central para a literatura austríaca. Como ilustra, por exemplo, W. G. Sebald, em Unheimliche Heimat - Essays zur österreichischen Literatur (A pátria sinistra - ensaios sobre a literatura austríaca), tal relevância desse tópico também está estreitamente relacionada a constelações e transformações históricas do país:

Devido aos desdobramentos, muitas vezes dramáticos, pelos quais a Áustria passou do vasto império habsburgo para a pequena república dos Alpes e desta, em decorrência da Ständestaat e da funesta anexação pela Alemanha, até a sua nova fundação nos anos pós-guerra, o complexo temático esboçado por termos como pátria, província, terra fronteiriça, terras estrangeiras, estrangeiro e exílio ocupa uma posição extraordinariamente importante. Poder-se-ia dizer que a discussão sobre a pátria constitui uma das características mais constantes através das rupturas históricas da literatura austríaca, que é geralmente de difícil definição [...]. (SEBALD 2004: 11).

$\mathrm{Na}$ Áustria do pós-guerra, o turismo tornou-se uma das mais importantes fontes da economia e também símbolo da nova identidade austríaca que se formou, entre outros fatores, a partir do país como sendo "bonito", repleto de belas paisagens. A literatura, num primeiro momento, correspondeu àquilo que se esperava dela por parte dos representantes do país, reforçando tal imagem. Depois, a repressão humana num ambiente rural aparentemente idílico, a continuidade de estruturas totalitárias e fascistas, a "liquidação" do país através do turismo tornaram-se motivos frequentes na literatura. De acordo com Höller,

[p]or volta de 1960, a reconstrução tinha praticamente chegado ao seu fim, a literatura começou a investigar o fundamento no qual os novos prédios tinham 
Bohunovsky, R. - À procura da literatura austríaca

sido construídos depois da guerra. O recalcado e o horrível sob a paisagem alegre do turismo, esse singular "grande hotel de esporte Áustria do oeste" (Heimito von Doderer) tornou-se seu tema, urgia em direção da província escura, nos municípios afastados e esquecidos. (HöLLER apud ZEYRINGER 2008: 117).

Podemos resumir que, na Segunda República, a literatura tem sido marcada por uma polarização entre uma perseverança pela continuidade de tradições conservadoras e por tentativas de se opor a essa tendência dominante. Nesse contexto, surgiu a vertente da “crítica à Áustria" (Lebert, Fritsch, Bernhard, G. Roth, J. Haslinger, Wiener Gruppe, Forum Stadtpark) - autores que continuam, embora na direção contrária a seus precursores da Primeira República (Hofmannsthal, Andrian, Wildgans), a discussão sobre a identidade austríaca. As reações críticas ao fortalecimento de um imaginário conservador e supostamente enraizado numa tradição milenar da Áustria aumentaram nos anos 70 de maneira mais sensível. Tais reações continuam até hoje, manifestandose, sobretudo, em forma de críticas severas contra a sobrevivência do pensamento do austro-fascismo e do fascismo nacional (por exemplo, na obra de Elfriede Jelinek). O topos da Heimat - muitas vezes, na forma de uma crítica a tal exaltada "beleza" do país - continua presente também na literatura mais recente, como ilustram duas passagens do poema “Österreich ist schön”, de Franzobel (nascido em 1967):

Österreich? Ist das schön. Und hundertmal \& überhaupt. Österreich ist schön, und schon schön ist Österreich.[...] So schön ist Österreich, daß schon die Schulkinder es aufschreiben müssen. Müssen schreiben: Österreich fängt schön an, und schön hört Österreich auch auf. Ja. So ist das mit Österreich. Durch und durch schön. Hundertmal. (apud FLEISCHANDERL; ERNST 2003: 9).

(A Áustria? Como é bela. E cem vezes \& em geral. A Áustria é bela e muito bela é a Áustria. [...] Tão bela é a Áustria que até as crianças na escola têm de escrevê-lo. Têm de escrever: a Áustria começa bela e a Áustria também acaba bela. Sim. É assim com a Áustria. Bela de cima a baixo. Cem vezes.)

Ou, nas palavras menos irônicas de Sebald: "Parece que ainda é difícil sentir-se em casa na Áustria" (SEBALD 2004: 15). 
Bohunovsky, R. - À procura da literatura austríaca

\section{Conclusão}

Partimos da premissa de que a literatura não surge num espaço a-histórico e que o contexto sócio-político pode ser relevante para sua interpretação. Assim como é evidente entender Machado de Assis e Jorge Amado como escritores brasileiros - e não portugueses -, as obras de autores austríacos devem ser estudadas e discutidas levando em conta o contexto específico no qual foram produzidas. Para muitos escritores austríacos, o país Áustria tem sido um ponto de referência importante, fundamental para seus textos ("Das Fette, an dem ich würge: Österreich") (A gordura que me sufoca: a Áustria) (HANDKE 1977: 21). Como procurei ilustrar neste trabalho, uma parte representativa da germanística austríaca procura chamar a atenção para as diferenças entre a literatura alemã e a austríaca, muitas vezes ignoradas por parte da crítica literária.

Ao estudar, em publicações mais recentes, as análises da literatura austríaca, torna-se evidente que a construção de um mito austríaco - vinculada à construção de uma identidade nacional - foi substituída por análises aprofundadas das peculiaridades sócio-históricas que têm interferido na produção literária do país. O que era visto como suposta essência do povo austríaco passa a ser percebido como vinculado a determinadas constelações sócio-políticas e/ou como topos literário. O fato de que as discussões atuais nesse sentido estão longe de pretender definir algo como um caráter nacional homogêneo pode ser ilustrado pela seguinte citação de Weiss, que resume também o interesse dos outros autores aos quais nos referimos neste trabalho:

Quem se aproximar da história literária da Áustria, terá de lidar com complexidade, pluralidade de níveis, cruzamentos de níveis, pluricentrismo, identidades múltiplas. [...] As mudanças e os constantes históricos do conceito da Áustria [...] são mais úteis para uma aproximação com a literatura austríaca do que o conceito de unidade de língua alemã e, em consequência disso, uma unidade étnica ou cultural. O conglomerado [...] "heterogeneamente plurilinguístico" deve - por fim também com vistas à futura Europa - ser levado a sério de maneira positiva (WEISS 1995: 27-28). 
Bohunovsky, R. - À procura da literatura austríaca

\section{Referências bibliográficas}

Bernhard, Thomas. Frost. In: Die Romane. Frankfurt am Main: Suhrkamp, 2008. (1. ed. 1963)

DODERER, Heimito von. Die Strudelhofstiege oder Melzer und die Tiefe der Jahre. München: dtv, 1977. (1. ed. 1966)

FleisCHANDERL, Karin; ERnSt, Gustav. Zum Glück gibt's Österreich: Junge österreichische Literatur. Berlin: Klaus Wagenbach, 2003.

Freitag, Wolfgang. Vom Brunzen und vom Schlürfen. Die Presse. Viena, 16 de janeiro de 2010, Spectrum, 3.

HABERMAS, Jürgen. Die Einbeziehung des Anderen: Studien zur politischen Theorie. Frankfurt: Suhrkamp, 1999.

HANDKE, Peter. Das Gewicht der Welt. Ein Journal. Frankfurt am Main: Suhrkamp, 1977.

JoHnStOn, William M. Der österreichische Mensch: Kulturgeschichte der Eigenart Österreichs. Wien, Köln, Graz: Böhlau Verlag, 2010.

MAGRIS, Claudio. Der habsburgische Mythos in der modernen österreichischen Literatur. Tradução do italiano de Madeleine von Pasztory e Renate Lunzer. Wien: Zsolnay, 2000. (1. ed. 1963)

Nitsche, Gerald; GITTERLE, Bruno. Neue österreichische Lyrik und kein Wort Deutsch. Innsbruch: Haymon, 2008.

SCHLAFFER, Heinz. Die kurze Geschichte der deutschen Literatur. 3. ed. München: dtv, 2008. (1. ed. 2003)

SCHMID, Georg; SCHMID-BORTENSCHLAGER, Sigrid. Österreichische Literatur Obsession und Phantasma. In: Modern Austrian Literature 17, 3-4, 1984: 113128.

SCHMIDT-DENGLER, Wendelin; ZEYRINGER, Klaus. Literaturgeschichte Österreichs. Einführung in die Problematik. In: SCHMIDT-DENGLER, Wendelin; et al. Literaturgeschichte: Österreich: Prolegomena und Fallstudien. Berlin: Erich Schmidt: 1995: 9-18.

SCHMIDT-DENGLER, Wendelin. Bruchlinien: Vorlesungen zur österreichischen Literatur 1945 bis 1990. 3. ed. St. Pölten, Salzburg: Residenz Verlag, 2010. (1. ed. 1995)

SEBALD, W.G. Unheimliche Heimat: Essays zur österreichischen Literatur. 3. ed. Frankfurt am Main: Fischer, 2004. (1. ed. 1995)

SEBALD, W.G. Die Beschreibung des Unglücks: Zur österreichischen Literatur von Stifter bis Handke. 5. ed. Frankfurt am Main: Fischer, 2006. (1. ed. 1994)

STRELKA, Joseph P. Zwischen Wirklichkeit und Traum: Das Wesen des Österreichischen in der Literatur. Tübingen und Basel: Francke, 1994.

WAGGERL, Karl Heinrich. Fröhliche Armut. Erzählung. Salzburg: Müller, 1986.

WeHRLI, Max. Gibt es eine deutsche Literaturgeschichte? In: Jahrbuch für Internationale Germanistik 2/1, 1970: 13-24.

WEISS, Walter. Ausblick auf eine Geschichte österreichischer Literatur. In: SCHMIDTDENGLER, Wendelin; et al. Literaturgeschichte: Österreich: Prolegomena und Fallstudien. Berlin: Erich Schmidt: 1995: 19-28. 
Bohunovsky, R. - À procura da literatura austríaca

WILDGANS, Anton. Rede über Österreich. Disponível em: <http://www.antonwildgans.at/page87.html>. (Acesso em: 21/02/2010).

ZEYRINGER, Klaus. Österreichische Literatur seit 1945: Überblicke, Einschnitte, Wegmarken. Innsbruck: Studienverlag, 2008. 